\title{
Dining out and weight management
}

\section{Opinion}

It is a general observation that one starts to put on weight when he prefers more dine outs mainly comprising of junk foods and drinks with family or friends at some parties or other business events. Only in few cases people tend to put on weight while eating at home when they mostly eat fast food or are sweet lovers. The main reason behind this science is that people usually remain fit \& well maintained in terms of weight because at home they usually keep changing the routine of meals as no one eats one type of food all over the week. They usually have different plans regularly including vegetables, meat \& some portion of carbohydrates alternatively.

The benefit of cooking at home is that we can control the amount of carbohydrates, sugar \& fat in comparison to junk food being eaten when we go out to eat. Because the home cook; usually the mother knows the amount and quality of different ingredients added to the particular food, she makes sure to make it more healthy nutrientwise rather than calorie-wise, whereas no one knows the amount and quality of the same ingredients in the food we eat outside except that the ingredients are much higher in quantity making it more calorie dense.

It is also observed that when we enter into colleges/universities or professional lives, we are bound to eat outside because we are too lazy to carry the lunchbox at our workplace. Moreover, eating homecooked meals on a regular basis doesn't mean you need to cook every now and then. We can cut ourselves a break by cooking large batches of every meal been made, so it can be reheated in office/university cafeteria.

Some studies also showed that those who ate more frequently at home also ate fewer calories when compared when they choose to eat out as they can limit the amount of sugar and fat in it. Although some restaurants are offering more nutritious food options these days, the choices are often limited and the cravings are much higher. Therefore, if you eat at home, you can choose your own low-fat and low-calorie ingredients to prepare your meals. This shows that eating at home is one of the best ways to promote a healthy lifestyle and limit calorie intake. ${ }^{1}$

To stay faithful with your diet plan if you are willing to reduce weight it's better to eat at home. Because dine-out will expose you to greater Temptation to eat Appetizing, unhealthy Food \& there is more chance that you will forget about your Diet restrictions while eating out with your friends. So to avoid over eating \& Temptation it's better to eat at home which allows you to Stick with your diet plan \& eat healthy Food. ${ }^{2,3}$ Eating nutritious food and living a healthy lifestyle will give you more energy, and it enables you to perform your daily duties with ease. Doing chores such as cooking and washing dishes
Volume 7 Issue 4 - 2017

\author{
Mateen Anwar,' Zainab Hussain ${ }^{2}$ \\ 'Food Technologist, Quality \& Food Safety Auditor, Saudi Arabia \\ ${ }^{2}$ Food Service Dietitian at Safe Food Caterers (SFC), Tabba \\ Heart Institute (THI), Pakistan
}

Correspondence: Mateen Anwar, Food Technologist, Quality \& Food Safety Auditor, Baskin Robbins, Riyadh, KSA, Email mateenanwer@yahoo.com

Received: September 22, 2017| Published: November 0I, 2017

will also make you more active, and it can help you become a more responsible person. Eating healthy meals at home can cut your food budget dramatically. When you consider that a healthy and satisfying meal can be prepared for the whole family in fewer amounts as compared to eating outside just with your wife.

High-fat/high-calorie foods do not provide the physical energy or the mental energy you and your family needs to thrive, and eating out is taking a dent out of your budget. For 2 weeks, forget eating out, and put all the money you have saved into a jar for a special evening out, a horseback ride, or a camping trip to a favorite destination. We can make family time even while eating a healthy nutritious food at our home. Eating at home offers an excellent opportunity for family bonding. You can talk to your children about school or your spouse about his day at work over dinner. It doesn't mean deciding to make meals at home will restrict so you would never enjoy Dine-out again. Schedule meals out in a month or week, or whatever schedule works for you - so that cooking meal at home never feels like a chore. Whether it's your first time to cook a meal in your life or you are tired because of your busy schedule, give a few of these tips a try, and commit to a few small lifestyle changes. You'll be on your way to living a healthier, happier life.

\section{Acknowledgements}

None.

\section{Conflicts of interest}

The author declares no conflict of interest.

\section{References}
1. 5 Ways to a Healthy Lifestyle.
2. 6 Reasons Why You Should Stop Dining Out.
3. 20 Simple Ways to Live a Healthy, Happy Life. 